Weinstein, S. (1992). Telling the untold story: How investigative reporters are changing the craft of biography. Columbia: University of Missouri Press.

Weinstein, E. A., Anderson, J. W., \& Link, A. S. (1978-1979). Woodrow Wilson's political personality: A reappraisal. Political Science Quarterly, 93, 586-594.

White, H. (1992). Historiography as narration. In J. H. Smith (Ed.), Telling facts: History and narration in psychoanalysis (pp.
284-294). Baltimore, MD: Johns Hopkins University Press. Whitfield, J. S. (1978). Three masters of impression management: Benjamin Franklin, Booker T. Washington, and Malcolm X as autobiographers. South Atlantic Quarterly, 77, 399-417.

Wineburg, S. S. (1991). Historical problem solving: A study of the cognitive process used in the evaluation of documentary and pictorial evidence. Journal of Educational Psychology, 83, 73-87.

\title{
Bridging Traits, Story, and Self: Prospects and Problems
}

\author{
Hubert J. M. Hermans \\ Department of Clinical Psychology and Personality \\ University of Nijmegen
}

In his target article, McAdams brings together three domains in the field of psychology in which challenging developments have been observed over the past decades: trait psychology, narrative psychology, and culture. Trait psychology has been rejuvenated by crossnational and cross-cultural research projects on the "Big Five." The narrative approach has cropped up in a great diversity of psychological subdisciplines, including personality psychology, and is on its way to being accepted as a respected development in academic psychology. The notion of culture has also received enormous interest, particularly in discussions around modernity and postmodernity and their implications for psychology as a science. Scientists in and outside psychology are becoming aware that culture is implicit not only in their personal views, but also in the theories and concepts that form the basis of their professional activities. McAdams's contribution has the merit that it provides an intriguing conceptual framework that aims at integrating a diversity of psychological developments that interact in many ways, but that have never been analyzed on their mutual implications from a metatheoretical point of view.

\section{Centrifugal Versus Centripetal Forces in Psychology}

To underscore the relevance and prospect of McAdams's proposal, it may be clarifying to locate his contribution in the context of the history of psychology as a discipline. As Altman (1987) proposed, a distinction can be made between centripetal forces (working toward unity and integration) and centrifugal forces (working toward differentiation and specialization). In every period in the history of psychology, centrifugal and centripetal forces have been present simultaneously. Despite this simultaneity, Altman argued that there are many indications that they are also alternately dominant in successive periods. He distinguished three periods: (a) the pre-1900 period, which was primarily centrifugal; (b) the period from 1900 to 1960, in which centripetal forces were at work; and (c) the period from 1960 to the present, in which centrifugal forces are predominant.

Altman (1987) observed strong centrifugal trends in psychological studies in the pre- 1900 period. The main reason was that early scholars of psychology were often to be found in various disciplines, such as philosophy, medicine, biology, or with no discipline at all. In that time there were no psychology departments, and early scholars explored psychological phenomena in an independent and noninstitutional fashion. As a consequence, there was little sense of a defined field of psychology with common values, methods, and approaches.

At the beginning of the second period, a variety of theoretical views manifested themselves as competing paradigms in the field of psychology, such as structuralism, functionalism, instinct theory, gestalt approaches, and behaviorism. Eventually, the behaviorist perspective, in its variants, became most dominant in American psychology. Although there were many differences among these variants, they collectively provided a unifying, centripetal anchor for psychology in 


\section{COMMENTARIES}

those years (e.g., theories of Watson, Hull, Tolman, and Skinner). In this period, nonbehaviorist theories also emerged as unifying theories, such as the field theory of Lewin, and the personality approaches of Murray and Allport. Altogether, "grand theories" were increasingly centripetal and fulfilled the needs for structure and integration for many psychologists.

In the third period, from 1960 onward, Altman (1987) observed that systems of education expanded and universities entered a phase of differentiation resulting in many disciplines and subdisciplines. Psychology departments became increasingly focused on their own development and excellence was usually measured by research productivity, publications, grant funds, and national visibility. More and more seminars were offered on narrower topics, and there was a premium on specialization. This proliferation of specialties, and the emergence of interest groups, functioned as a strong centrifugal force that led to the loss of a common core of ideas in psychology as an integrative discipline.

In comparing the two forces, Altman (1987) explicitly emphasized that he does not consider one of the two forces as "better" than the other:

I must reiterate that neither centrifugal nor centripetal trends are intrinsically "good" or "bad." One can praise or decry centripetal trends, for example, as reflecting status quo and stagnation on the negative side, or unity, harmony, and stability on the positive side. Similarly, centrifugal trends can be viewed negatively, for example, as indicating divisiveness and disunity, or positively, for example, as allowing for enrichment and exploration of new directions ... we should not evaluate either trend as intrinsically good or bad. Rather we should attempt to assess their respective strengths, directions, and characteristics in order to adjust to and capitalize on their qualities. (pp. 1062-1063)

In a similar vein, McAdams compares "grand theories" (e.g., Freud, Lewin, and Murray) in the first half of this century with the empirical work on psychological constructs (e.g., need for achievement, self-monitoring) by contemporary researchers in personality psychology. He evaluates both developments on their relative strength instead of rejecting one in favor of the other. He criticizes, for example, the grand theories for being "too general and ambiguous" but, at the same time, emphasizes the integrative potential of such endeavors. On the other hand, he criticizes the fragmented picture of personality, resulting from research on "pet variables" by contemporary personality researchers, but he values their empirical and methodological contributions to the field. I consider McAdams's new integrative framework to be a bold attempt to keep the integrative power of more comprehensive theorizing while avoiding the pitfalls of overgenerality and being out of touch with empirical work on specific psychological constructs.

From the perspective of historical developments in psychology, I see McAdams's proposal as representing the beginning of a new centripetal period in psychology, one that is reacting to the fragmented picture of personality psychology of the postwar period. The difference with the period of the grand theories, however, is that his proposal is situated on a medium level of comprehensiveness and generality. Constructing a theoretical framework on this level has the advantage that it is sufficiently in touch with empirical work on specific psychological constructs and, at the same time, profits from a broader, integrative view.

In the following, I analyze and critically discuss three aspects of McAdams's proposal: (a) the combination of contextualized and decontextualized elements in one conceptual framework; (b) integration as an intrinsic feature of story; and (c) the distinction between narrative and postnarrative eras in human life.

\section{The Combination of Contextualized and Decontextualized Elements}

The proposed framework aims to combine and integrate contextualized and decontextualized elements in a three-level model. The first level refers to decontextualized elements (traits), whereas the second and third level represent contextualized elements: personal concerns and unity of life, respectively. How can decontextualized elements combine with contextualized elements? McAdams seems to be aware that there is a problem, when he describes the differences between Level 1 constructs and the notions on the other levels. $\mathrm{He}$ argues that trait descriptions yield little beyond a "psychology of a stranger"-that is, as reliable and valid trait ratings they may provide a very useful "first read" on a person. Such information is characterized as comparative and relatively nonconditional. A highly extraverted person, for example, acts in an outgoing and sociable way compared to most other people (comparative) and tends to act in quite a wide variety of situations (nonconditional). How can data of this kind become meaningfully related to the personal concerns on Level 2 and unity of life on Level 3, which are typically noncomparative and highly conditional and can only become well understood in the context of the person's life situation?

The problem of combining contextualized and decontextualized elements becomes even more articulated 
by McAdams's disagreement with McCrae and Costa's proposal that contextualized constructs like goals and strivings may be viewed as "characteristic adaptations" that are derived from the interaction of basic traits and environmental contingencies. In his contra-argumentation, McAdams refers to work from Kaiser and Ozer, who found that personal goals ("motivational units") do not map into the five-factor structure. Instead, this study suggests that the structure of personal concerns may be more appropriately conceptualized in terms of various content domains (e.g., work, social). In other words, McAdams is aware that there is a problem with integrating the decontextualized Big Five on Level 1 with the contextualized data on the other levels. How then are the levels related and integrated?

Within the constraints of the proposed conceptual framework, the integration of the different levels should derive from the selfing process. In McAdams's terms:

In personality, the I may be viewed as the process of "selfing," of narrating experience to create a self, and the Me may be viewed as the self that the I narrates. The three levels hold a wide assortment of personal characteristics that are, in principle, potential components of the self-that is, potential characteristics of the Me that the I constructs.

In other words, any aspect of personality, concern, or story may, in principle, be a potential part of the self, and the person may make it "mine" through selfing. Again, McAdams is aware of the problem that is created by this theoretical construction. He adds that personality is not synonymous with the self-concept because (a) some parts of the Me are not aspects of personality (e.g., my dog, my clothing); and (b) some parts of personality may not be the targets of selfing, even though in principle they could be (e.g., unconscious material). However, the problem may be more profound than McAdams is suggesting here.

The following question has to be answered. When it is explicitly stated that "the Me is the primary product of the selfing process. It is the self that selfing makes," how then can decontextualized traits, which are not the product of selfing, be part of the Me that is, from a theoretical perspective, the product of selfing? McAdams's answer to this question is that traits, originally decontextualized, may become "owned" by the self as a result of the selfing process. Along these lines, general traits may become incorporated into the self as personalized and conditionalized features so that they become contextualized.

However, this processing part of the model leaves a central question unanswered: How can a trait, as a potential candidate for the self, become a real part of the self? In addressing this question, explicit attention should be given to the processing of traits from the moment a particular trait is selected for inclusion in the self to the storing of the trait as an actually owned part of the self. Although the model acknowledges the agentic features of the self, in terms of a selfing process, it does not clarify how the processing goes from decontextualized traits to contextualized self components.

\section{Imagoes As Voiced Characters}

The problem of the contextualization of traits has my greatest interest, because in our research (Hermans, 1996a; Hermans \& Kempen, 1993) we have dealt with similar problems. Inspired by the Bakhtinian metaphor of the "polyphonic novel," we have conceived of traits as "voiced characters" that may entertain mutual dialogical relationships. Using a self-confrontation method, we invited participants to select opposite trait pairs (comparable with Kelly's personal constructs) that play a major role in their everyday lives (e.g., open vs. closed). Each trait was then defined as a relatively autonomous character (subself) in one's life. The participant was invited to formulate a variety of personal meaning units (valuations in our terms) referring to past, present, and future. This was done apart from the position of "I as an open person" and from the position of "I as a closed person," and this resulted in two valuation systems, one associated with the open character and another associated with the closed character. We followed the characters over time and found not only apparent contradictions between the personal content associated with the traits, but also clear instances of dominance reversal over time (e.g., the closed character that was initially less dominant than the open character becomes eventually more dominant).

The rationale behind this research strategy is that traits are or may become highly personal and contextualized when, as voiced characters, they tell about their personal meaning units. From this point of view, McAdams's notion of "imago," which he defines as "an idealized personification of the self that functions as a main character in narrative," is a highly relevant one. If conceived as voiced, the imago would have the capacity to tell, as a subself, a story filled with personalized and contextualized meaning units. In McAdams's model, traits conceived as voiced imagoes could tell their own stories that have their specific narrative tone, imagery, themes, ideological settings, and nuclear episodes. To sum up, voicing the concept of imago would allow a conceptual bridge for contextualizing trait categories. (For an extensive treatment of voicing the self, see Hermans, 1996b.) 


\section{Integration: An Intrinsic Feature of Story?}

On Level 3 of the proposed model, we find two notions that seem to be treated as two sides of a coin: (a) the unity of the self and (b) the construction of a life story. The combination of these notions, and their significance for the modern self, is well expressed in this passage:

Level 3 presents personality concepts that are especially derivative of adult life in modern societies. In modernity, a full description of adult personality commonly requires a consideration of the extent to which a human life expresses unity and purpose, the hallmarks of identity for the reflexive project of the modern self. At Level 3, then, reside the psychosocial constructions that constitute identity. In the modern world, such constructions assume the form of stories of the self-internalized and evolving life stories that integrate the reconstructed past; perceived present, and anticipated future.

As this and other passages suggest, the notion of story implies the unity and integration of the self. To what extent is this implication warranted?

McAdams is well aware of the possibility that people offer different stories about themselves in different contexts. Referring to the work of Goffman (1959) and Hogan (1987), he points to the demand characteristics of everyday life requiring that people operate in strategic ways to manage the impressions of others, seeking status and acceptance in their self-defining groups: "Therefore, the story I tell you about myself on a first date may be very different from the one I tell at the office the next day or the one I tell my therapist next week." He even admits that a person may tell more than one life story or that "the overall life story itself may consist of a collection of rather disconnected stories about the self." His answer to these possibilities is that "the adult selfing process seems to seek out opportunities for integrating different autobiographical accounts into a narrated whole, aiming to construct a Me that exhibits a modicum of unity, coherence, and purpose."

Indeed, there is much evidence in the psychological literature that people are able to tell disconnected stories. A well-known example is the famous case study of Eve White and Eve Black (Thigpen \& Cleckley, 1954), two characters, within the same person, that were each able to tell a separate story about themselves, but were not able to communicate with each other in a direct way. Instead, the one character could only talk about the other in a rather objectifying way (consistently speaking about "she"). In our own research with clients in counseling and psychotherapy (Hermans \& Her-
mans-Jansen, 1995), we have also found that people, both those with dysfunctions and those without dysfunctions, may tell life stories showing a considerable amount of unity and consistency within a particular subself, but at the same time exposing many inconsistencies between different subselves.

What is the theoretical implication of the existence of disconnected stories within one person? When people tell life stories with quite unrelated components, at what level does the concept of story belong in the proposed model? A person may tell a multiplicity of stories, in the same way that he or she may tell about a multiplicity of personal concerns or tasks. At what level should this multiplicity be placed? It is McAdams's position that the synthesis and unity of the self is on Level 3. His supposition is, moreover, that the life story has so much integrative potential that it should also be placed, for that reason, on Level 3. There is, however, a counterargument to this combining the concepts of integration and life story on Level 3. When stories may be as disconnected as concerns, tasks, and goals, then the notion of story itself should, in my view, be added to Level 2 and not to Level 3. The notion of integration, the synthetic function of selfing, has its proper place on Level 3, in accordance with McAdams's view. It is this synthetic function that integrates not only diversified tasks, concerns, and goals, but also the multiplicity of stories that results from the great variation of positions corresponding with changes in time, place, and role. There is no theoretical necessity for binding synthesis exclusively to story, because a story has no more or less integrative power than a goal or a task. McAdams refers to Loevinger's (1976) theory of ego development as an example of the synthetic function of the ego. In this theory, the synthetic quality of the process of selfing is on the highest levels of ego development, but it is not exclusively defined in narrative terms.

\section{The Distinction Among Prenarrative, Narrative, and Postnarrative Eras}

From a developmental view, McAdams distinguishes between prenarrative, narrative, and postnarrative eras in life. The prenarrative era covers infancy, childhood, and early adolescence. The narrative era runs from some point in adolescence or young adulthood when the individual begins to create a self-defining life story through most, if not all, of adulthood. The postnarrative era occurs synonymously with Erikson's (1963) stage of ego-integrity versus despair.

In the postnarrative era, McAdams adds, the elderly person looks on his or her life as something that has been reviewed or may now be reviewed as a near-fin- 
ished product, "a complete story that may be accepted (integrity) or rejected (despair) but which can no longer be substantially changed." In my view, there are two reasons why I have doubts about this qualification and delineation of a postnarrative era, one of a theoretical and another of an empirical nature.

First, McAdams introduces a particular criterion for making the distinction between the narrative and postnarrative era: The final era is postnarrative because it can no longer be substantially changed. In his previous argument, however, the essential defining feature of a life narrative is its integrative or synthesizing function. If we take the latter criterion as the essential one, then the era in which the person is doing a large amount of integrative work - that is, in Erikson's stage of ego integrity versus despair-should be a narrative era par excellence. In this case there would not be much reason to define late adulthood as postnarrative.

Second, there are empirical reasons for considering late adulthood as a period in which the self is confronted with many changes that require a continued organization and reorganization of one's life narrative. Kastenbaum (1977), for example, has emphasized that death is particularly influential in the lives of elderly people. The longer one lives, the greater the number of intimate companions one outlives. This may even reawaken anxieties about separation and loss that have been with the individual since early childhood. The elderly are in particular jeopardy, because they are likely to experience a greater number of bereavements. Before they have been able to "work through" the death of a loved person, another may die. Under these circumstances, Kastenbaum (1969) wrote of "bereavement overload" (p. 48).

Moreover, late adulthood, at least in our culture, can be marked by a combination of "role loss" and "object loss." The former is characterized by a disruption of a functional relationship in society and the latter by the falling away of significant others (Averill, 1968). When people are losing significant others and are not able, as in earlier times, to find meaningful compensation in work or other societal activities, their self-system is seriously threatened by the risk of depression. Changes of this kind are quite typical of late adulthood and require a continuous reorganization of one's life narrative. Taking the theoretical and the empirical argument together, I believe that there is reason enough to consider late adulthood, from a narrative point of view, as an era in which significant life events continue to challenge the integrative capacities of the self. (Note that I have restricted my discussion to the postnarrative era; I do not exclude that a similar analysis could be made of the prenarrative era.)

\section{Conclusion}

In summary, I consider McAdams's multilevel approach as representing the beginning of a new era in psychology in which centripetal forces are evoked as a reaction to the preceding era in which centrifugal forces were dominant. The proposed model is comprehensive enough to offer a broad theoretical view and is, at the same time, sufficiently sensitive and flexible to incorporate a diversity of research findings on specific psychological constructs. In my analysis I have concentrated on three issues that may require a further articulation or revision of the model: the combination of contextualized and noncontextualized elements, the integrative function of story, and the distinction between narrative and postnarrative eras in human lives.

\section{Note}

Hubert J. M. Hermans, Department of Clinical Psychology and Personality, University of Nijmegen, P.O. Box 9104, 6500 HE Nijmegen, The Netherlands.

\section{References}

Altman, I. (1987). Centripetal and centrifugal trends in psychology. American Psychologist, 42, 1058-1069.

Averill, J. R. (1968). Grief: Its nature and significance. Psychological Bulletin, 70, 721-748.

Erikson, E. (1963). Childhood and society (2nd ed.). New York: Norton.

Goffman, E. (1959). The presentation of self in everyday life. Garden City, NY: Doubleday.

Hermans, H. J. M. (1996a). Opposites in a dialogical self: Constructs as characters. Journal of Constructivist Psychology, 9, 1-26.

Hermans, H. J. M. (1996b). Voicing the self: From information processing to dialogical interchange. Psychological Bulletin, $119,31-50$.

Hermans, H. J. M., \& Hermans-Jansen, E. (1995). Self-narratives: The construction of meaning in psychotherapy. New York: Guilford.

Hermans, H. J. M., \& Kempen, H. J. G. (1993). The dialogical self: Meaning as movement. San Diego: Academic.

Hogan, R. T. (1987). Personality psychology: Back to basics. In J. Aronoff, A. I. Rabin, \& R. A. Zucker (Eds.), The emergence of personality (pp. 79-104). New York: Springer.

Kastenbaum, R. (1969). Death and bereavement in later life. In A. H. Kutscher (Ed.), Death and bereavement (pp. 28-54). Springfield, IL: Thomas.

Kastenbaum, R. (1977). Death and development through the lifespan. In H. Feifel (Ed.), New meanings of death (pp. 17-45). New York: McGraw-Hill.

Loevinger, J. (1976). Ego development. San Francisco: Jossey-Bass.

Thigpen, C. H., \& Cleckley, H. (1954). A case of multiple personality. Journal of Abnormal and Social Psychology, 49, 135-151. 